\title{
PEMBUATAN PERAHU NELAYAN BERBAHAN KOMPOSIT SANDWICH DENGAN TEKNIK HAND LAYUP
}

\section{MANUFACTURE OF COMPOSITE SANDWICH FISHING BOAT WITH THE HAND LAY UP TECHNIQUE}

\author{
Agus Dwi Catur \& Salman
}

\author{
Jurusan Teknik Mesin, Fakultas Teknik, Universitas Mataram \\ Jl. Majapahit 62 Mataram 83000 Telp 0370636087 fax 0370636523 \\ e-mail : agus_dc1@yahoo.co.id \\ Diterima tanggal: 15 Desember 2016; diterima setelah perbaikan: 13 Agustus 2020 ; Disetujui tanggal: 13 Agustus 2020
}

\begin{abstract}
ABSTRAK
Perahu kayu masih mendominasi sebagai alat mencari ikan oleh nelayan. Semakin mahalnya dan terbatasnya kayu membuat perahu kayu menjadi mahal. Diperlukan perahu yang ringan setara dengan perahu kayu tetapi tetap kuat sebagai alternatif penggantinya. Prototype perahu berbahan komposit sandwich dengan penguat serat bambu-fiberglass dan dengan core berupa polyurethane rigid foam telah dirancang dan dibuat dengan teknik hand lay up. Cara pembuatan perahu, jumlah material, alat yang dipakai, jumlah tenaga kerja dipelajari dan dihitung agar dapat dipakai sebagai acuan dalam memproduksi perahu berbahan komposit sandwich.. Bahan core lambung perahu nelayan dibuat dengan mereaksikan polyisocyanate dan polyol cair yang membentuk polyurethane foam di dalam cetakan. Sedangkan skin lambung perahu dibuat dengan melaminasi core lambung perahu dengan komposit resin diperkuat fiber glass dan anyaman bambu. Bagian utama perahu yang dibuat dari kayu adalah baruyungan dan dudukannya, tiang pancang layar, dudukan mesin, sedangkan cadik dibuat dari pralon PVC. Jumlah bahan, peralatan serta jumlah orang yang diperlukan pada setiap tahap pembuatan perahu ditabulasikan pada tulisan ini. Teknik hand lay up sangatlah sederhana, tidak memerlukan peralatan yang banyak maupun canggih sehingga mudah diterapkan bahkan oleh nelayan tradisional. Bahan untuk membuat perahu nelayan berbahan komposit sandwich juga mudah di dapat dan dalam jumlah yang tidak banyak dengan harga yang terjangkau. Pengerjaan pembuatan perahu nelayan berbahan komposit sandwich dengan teknik hand lay up memerlukan tenaga manusia sebanyak 12 orang hari.
\end{abstract}

Kata kunci: komposit sandwich, hand lay up, perahu.

\section{ABSTRACT}

The wooden boats are still dominating as transport equipment to fishing. The more expensive and limited wood to make wooden boats to be expensive. Required lightweight boat similar to wooden boats but still strong as alternatives. Prototype boat made of sandwich composite has been designed and made by hand lay-up techniques. Ways of making boats, the amount of material, equipment used, the number of workers studied and calculated to be used as reference in producing boats made of sandwich composite. Sandwich hull is made of polyurethane rigid foam and laminated by skin composite. Sandwich core prepared by reacting polyisocyanate and polyol liquid, and polyurethane rigid foam formed in the mold. The skin is made by laminating sandwich core with glass fiber and woven bamboo reinforced resin composites. The main part boat made of wood is baruyungan and its holder, piling screen, the engine support, while the outrigger is made of PVC pralon. The amount of material, equipment, the number of people required at each stage of manufacture of the boat are tabulated in this article. Hand lay up techniques is very simple, does not require advanced equipment and so many easily implemented even by traditional fishermen. Materials for making fishing boats made of composite sandwich is also accessible and in an amount which is not much at an affordable price. Manufacturing of sandwich composites fishing boat with hand lay up technique requires human labor as many as 12 people a day.

Keywords: sandwich composites, hand lay up, boat.

Pembuatan Perahu Nelayan Berbahan Komposit Sandwich dengan Teknik Hand lay up - Agus Dwi Catur \& Salman 


\section{PENDAHULUAN}

Jenis alat transportasi yang realistis yang dipakai penduduk untuk menghubungkan pulau-pulau kecil yang berdekatan adalah perahu. Selain untuk penghubung antar pulau kecil (gili) sebagai pengangkut penumpang dan barang, perahu digunakan oleh nelayan untuk mencari ikan. Perahu kayu sudah dikenal dan dikembangkan sejak nenek moyang. Perahu yang berukuran kecil kurang dari 5 Gross Ton dengan harga terjangkau menjadi pilihan nelayan kecil untuk mencari ikan di daerah 10 mil dari pantai (mikrofishing). Perahu ini digerakan mesin dengan poros panjang yang ditempel pada dudukannya di atas perahu. Perahu kecil yang digunakan nelayan tradisional di Nusa Tenggara Barat adalah perahu ketinting yaitu perahu dengan penggerak mesin as panjang yang disebut mesin ketinting. Pengoperasian perahu ini menjadi pilihan nelayan kecil untuk menangkap ikan di sekitar pantai karena tidak memerlukan ijin operasi dan retribusi.

Perahu berbahan non-kayu dikembangkan untuk menggantikan perahu kayu. Hal ini sejalan dengan isu pengundulan hutan yang meluas, maka penggunaan kayu sebagai perahu harus ditekan. Upaya penghematan kayu harus dilakukan termasuk dalam pembuatan perahu dan kapal. Umur perahu kayu kualitas rendah sangat pendek, hanya dalam 5 tahun sudah harus mengalami perbaikan besar karena pelapukan. Beberapa bahan yang telah dipakai untuk perahu selain kayu antara lain adalah baja, aluminium, komposit plastik diperkuat fiber glass (glass fiber reinforced plastic/GFRP). Aluminium dan baja yang mempunyai berat jenis sangat tinggi dibandingkan air laut. Aluminium mempunyai berat jenis $2.700 \mathrm{~kg} / \mathrm{m}^{3}$, sedangkan baja mempunyai berat jenis $7.850 \mathrm{~kg} / \mathrm{m}^{3}$. Selain itu bahan logam untuk perahu memerlukan perawatan yang ekstra ketat karena mempunyai sifat korosif. GFRP mempunyai kekuatan tarik mencapai $800 \mathrm{MPa}$ pada kandungan fraksi volume fiber glass maksimal 70\% (materials sciences corporation, 2002). Berat jenis GFRP dapat mencapai $1.400-1.990 \mathrm{~kg} / \mathrm{m}^{3}$ (East coast, 2013) lebih besar daripada berat jenis air laut $1030 \mathrm{~kg} / \mathrm{m}^{3}$ sehingga perahu dengan bahan GFRP akan tenggelam di laut jika mengalami kebocoran, pecah, atau terisi air karena terkena ombak besar. Perahu kayu akan mengapung walaupun perahu pecah, karena berat jenis kayu rata-rata lebih kecil dari berat jenis air laut yaitu sekitar $620 \mathrm{~kg} / \mathrm{m}^{3}$ (Catur, 2009).

Kekuatan tekan bambu utuh antara 47 - 93,6 MPa pada arah longitudinal dengan modulus elastisitas bending
(MOE) dapat mencapai 7,7-19,6 GPa (Xiaobo Li, 2004). Kekuatan tersebut lebih tinggi jika bambu dibuat menjadi strip-strip yang disatukan dengan matrik membentuk komposit. Komposit polimer yang diperkuat dengan anyaman bambu adalah bahan yang terdiri dari lapisan-lapisan strip anyaman bambu yang disatukan dengan matrik berupa resin. Bambu secara langsung berupa batang sudah banyak digunakan untuk komponen struktur seperti rangka rumah, jembatan, furniture, kentongan dan lainnya. Batang bambu yang kering mampu dibelah menjadi sangat tipis dan kemudian dianyam. Produk strip bambu yang mempunyai nilai seni adalah yang biasanya dibuat anyaman untuk berbagai macam barang rumah tangga, dinding, dan furniture. Produk-produk tersebut disukai karena mempunyai nilai seni, ramah lingkungan, food grade dan juga ramah terhadap manusia (Bansal et al., 2002). Untuk mengguatkan bahan matrik seperti epoxy, polyester maupun dengan polypropilen, bambu harus dibuat dalam bentuk strip ataupun serat (Thwe et al., 2002; Jain et al., 1992). Serat bambu dapat berfungsi sebagai material alternatif untuk menggantikan seratserat sintetis bila diolah dan diproses menjadi komposit. Kekuatan strip bambu lebih tinggi daripada dalam bentuk batang bambu utuh (Shukla et al., 1988).

Untuk mendapatkan perahu yang ringan tetapi kaku dan kuat harus diaplikasikan bahan yang ringan kaku dan kuat yaitu komposit sandwich. Konsep struktur panel yang terdiri dari dua laminat paralel tipis mengapit core merupakan struktur komposit sandwich yang umum diterapkan. Laminat paralel tipis dengan modulus elastisitas tinggi sebagai kulit digabung dengan core yang ringan sehingga diperoleh kombinasi bahan yang kaku, kuat dan ringan. Panel komposit sandwich dengan inti polyurethane rigid foam dilapisi kulit yang dikuatkan dengan anyaman bambu-fiber glass telah dibuat dan diuji kekuatanya (Catur, 2014). Kulit komposit berupa laminat dengan fraksi volume $15 \%$ fiberglass - $15 \%$ anyaman bambu mempunyai kekuatan tarik 15,3 kg/ mm² (setara $150 \mathrm{MPa}$ ). Hal ini memenuhi kekuatan tarik yang ditetapkan oleh Biro Klasifikasi Indonesia untuk kapal berbahan resin yang dikuatkan fiberglass yaitu sebesar $10 \mathrm{~kg} / \mathrm{mm}^{2}$ ( setara $98 \mathrm{MPa})$.

Teknik membuat lambung perahu komposit sandwich yang telah dilakukan industri perkapalan saat ini adalah menempelkan core pada cetakan dengan paku atau sekrup. Bahan core dipanaskan dan dilengkungkan pada cetakan sehingga kelengkungan core mengikuti cetakan. Setelah core terbentuk menjadi lambung, kemudian laminasi untuk membuat kulit lambung luar 

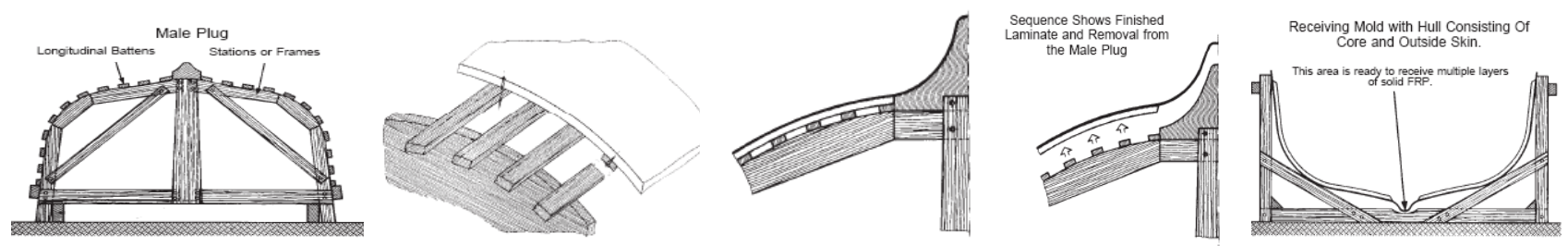

Gambar 1. Detail konstruksi sandwich dalam pencetakan.

Figure 1. Detailed Construction Sandwich in manufacturing.

Sumber: Greene E.,1999

maupun kulit lambung dalam Urutan proses tersebut ditunjukkan pada Gambar 1. Proses laminasi dapat dilakukan dengan berbagai teknik yaitu: hand lay up, spray up, compression molding, filamen winding, pultrution, vacuum bag molding, autoclave molding, resin transfer molding.

Penerapan komposit sandwich pada pembuatan perahu dan teknik pembuatanya yang lebih mudah dikaji agar penerapan oleh masyarakat industri maupun nelayan kecil cepat terlaksana. Teknik hand lay up adalah teknik yang mudah dilakukan bahkan oleh orang yang baru belajar memproduksi komposit GFRP. Pada tulisan ini dibahas pencetakan core perahu, dan teknik hand lay up untuk melaminasi core perahu membentuk kulit sandwich perahu. Jumlah bahan, peralatan yang dipakai dan jumlah tenaga kerja yang diperlukan dibahas pada tulisan ini agar dapat dimanfaatkan oleh khalayak masyarakat industri maupun nelayan kecil sebagai acuan.

\section{BAHAN DAN METODE}

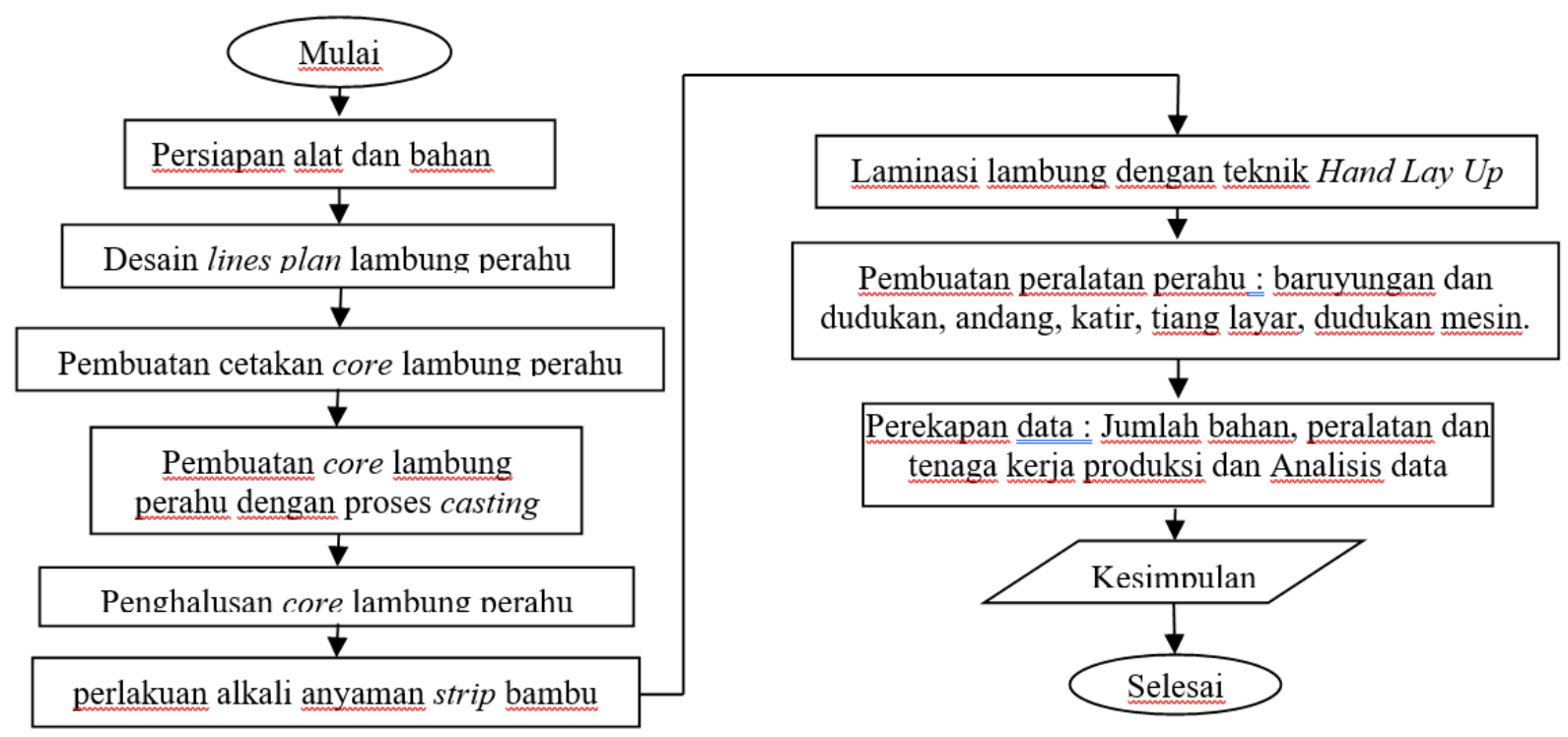

Urutan pelaksanaan penelitian dituangkan dalam diagram alur penelitian Gambar 2. Penelitian dimulai dari persiapan alat dan bahan yang dipakai untuk mencapai tujuan penelitian ini yaitu: kertas HVS, spidol, ballpoint, kertas minyak, penggaris $1 \mathrm{~m}$, multipleks $12 \mathrm{~mm}$, tripleks melamin $2 \mathrm{~mm}$, kayu usuk, paku, pilles 2,5 cm, gergaji mesin, ember $10 \mathrm{lt}$, polyol (polyurethane A-side), polyisocyanate (polyurethane $B$-side),ember, timbangan, takaran volume, mesin pengaduk, mesin serut, mesin gerinda tangan, resin polyester yukalac 157, hardener, fiber glass $200 \mathrm{gr} /$ $\mathrm{m}^{2}$, anyaman strip bambu, amplas, mata gerinda, capi plastik, kuas 2,5", kuas rol, talk, pigmen kuning, thinner, cat.

Desain lines plan perahu dibuat berdasarkan survei kepada nelayan bahwa perahu ketinting yang mereka harapkan adalah perahu yang ramping ringan sehingga dapat ditarik oleh dua orang nelayan sewaktu turun melaut maupun mendarat. Perahu nelayan didesain dengan panjang 4 meter, lebar 0,52 meter dan tinggi 0,8 meter seperti terlihat lines plan pada Gambar

Gambar 2. Diagram alur penelitian.

Figure 2. Flow chart of the study. 


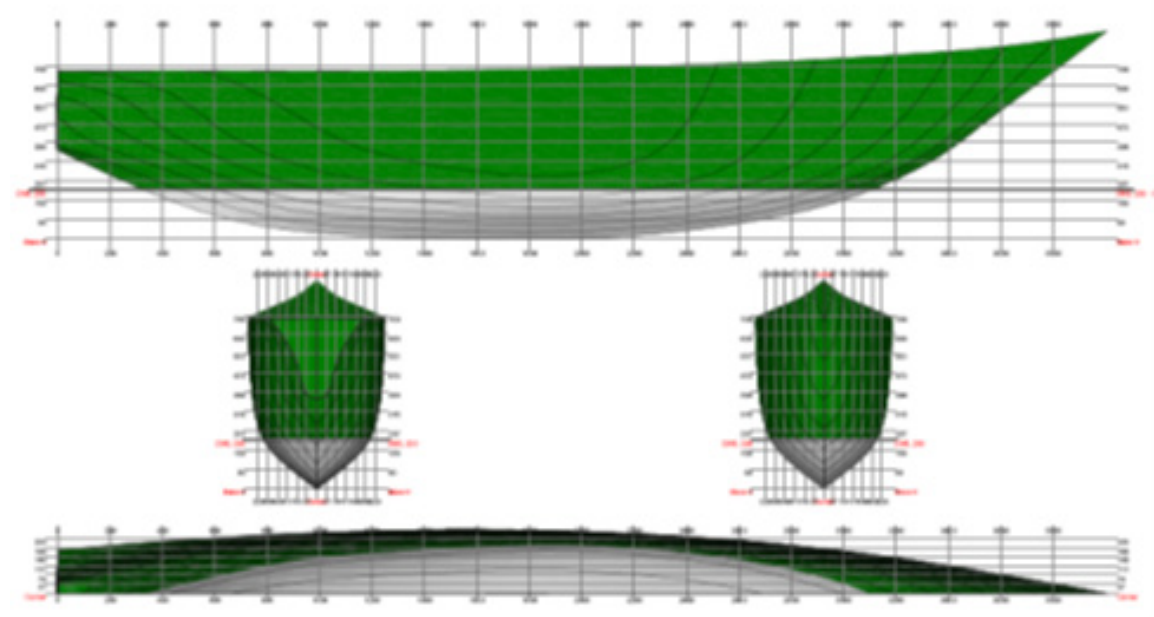

Gambar 3. Lines plan perahu yang dikembangkan.

Figure 3. Lines plan of developed boat.

Sumber: Dokumentasi pribadi

3. Lines plan dibuat dengan program delftship versi free 6.27.259. Lines plan pandangan depan kemudian dicetak dengan skala $1: 1$ yang merupakan mal frame cetakan core lambung perahu (Gambar 4a). Bila printer tidak memadai maka untuk memudahkan dalam pencetakan dapat dilakukan pencetakan sepotongsepotong kemudian disatukan.

Langkah penelitian berikutnya adalah pembuatan cetakan core lambung perahu, pembuatan core lambung perahu dengan proses casting, penghalusan core lambung perahu, perlakuan alkali anyaman strip bambu, laminasi lambung dengan teknik Hand lay up. Dalam setiap tahapan tersebut harus selalu dicatat jenis dan jumlah bahan yang dipakai, jenis dan jumlah peralatan yang dipakai serta jumlah tenaga manusia Pembuatan perahu berjumlah 3 buah dengan cetakan core yang sama. Dari ketiga pembuatan perahu tersebut, perekapan data rata-rata dilakukan untuk menentukan total jenis dan jumlah bahan, jenis dan jumlah peralatan serta jumlah tenaga kerja untuk memproduksi perahu berbahan komposit sandwich.

\section{HASIL DAN PEMBAHASAN}

Pada penelitian ini core lambung perahu dibuat bukan dengan cara menempel foam seperti metode yang diungkapkan oleh Greene (1999) tetapi dengan cara mencetaknya. Cara ini mempunyai beberapa kelebihan yaitu:

- Biaya pengangkutan dan penyimpanan bahan lebih murah karena polyurethane dalam keadaan cair yang kemudian dicetak menjadi core perahu dalam bentuk foam. Sedangkan metode penempelan membutuhkan lembaran polyurethan dengan volume bahan sudah besar.

- Tidak memerlukan panas untuk membuat core perahu, sedangkan pada metode penempelan membutuhkan panas untuk melengkungkan polyurethan foam.

- Core perahu yang tercetak utuh tanpa sambungan dan lebih halus. Sedangkan pada metode penempelan, core perahu merupakan lembaran polyurethan foam yang disambung-sambung sehingga tampak lekukan sambungan.

- Ketebalan bagian-bagian core perahu dapat diatur dengan mengatur rongga cetakan. Sedangkan pada metode penempelan, ketebalan core perahu diatur dengan menambal dan mengiris lembaran polyurethan foam. Sehingga metode pencetakan core perahu lebih menghemat bahan.

- Waktu pengerjaanya lebih singkat yaitu hanya dengan menuangkan polyurethane cair ke dalam cetakan dan terbentuklah core perahu polyurethane foam. Sedangkan pada metode penempelan polyurethane foam dengan mengikatnya ke cetakan memerlukan waktu yang lebih lama.

Metode pencetakan core perahu bukannya tanpa kekurangan. Polyol (polyurethane A-side) dan polyisocyanate (polyurethane B-side) yang merupakan bahan baku polyurethane foam adalah bahan yang mudah menguap sehingga butuh penanganan khusus dalam penyimpanannya. Namun pemakaian kedua bahan itu segera setelah dibuka penutup botolnya akan memberikan hasil yang sempurna.

Pencetakan core perahu dimulai dengan mencampur polyisocyanate dan polyol dengan perbandingan $1: 1$, 

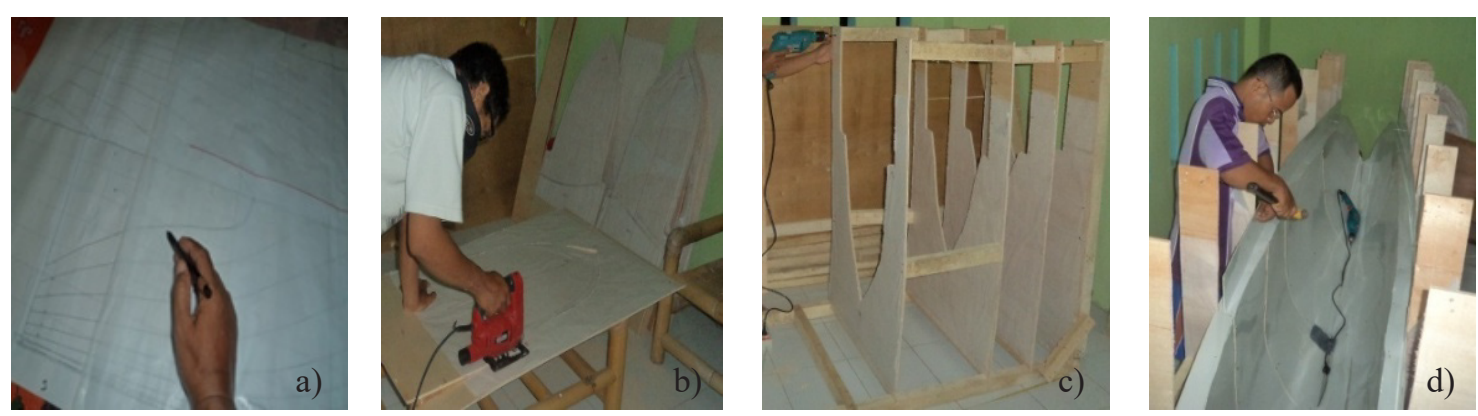

Gambar 4. Pembuatan cetakan luar core lambung perahu.

Figure 4. Making the outside molds of the boat hull core.

Sumber: Dokumentasi pribadi

mengaduk dan menuangkan ke dalam cetakan. Cetakan core perahu terdiri dari cetakan dalam dan cetakan luar. Frame cetakan luar dibuat dari multipleks yang dibentuk dengan gergaji sesuai mal frame (Gambar 4b). Frame cetakan dirangkai pada rangka kayu $4 \mathrm{~cm}$ x $6 \mathrm{~cm}$ dengan jarak antar frame $40 \mathrm{~cm}$ (Gambar 4c). Panjang perahu $400 \mathrm{~cm}$ sehingga frame berjumlah 11 . Cetakan core lambung perahu terbuat dari tripleks melamin yang ditempelkan pada frame cetakan mengikuti permukaan sisi tipis multiplek dan dipaku sehingga membentuk kontur lambung perahu bagian luar sesuai desain lines plan perahu (Gambar 4d). Demikian juga dengan cetakan dalam core lambung, frame dibuat dengan mengergaji multipleks yang telah ditempeli mal frame (Gambar 5.a).

Core lambung perahu dirancang mempunyai ketebalan $25 \mathrm{~mm}$ sehingga mal frame lambung dalam merupakan mal frame lambung luar dikurangi $30 \mathrm{~mm}$ masuk ke dalam dengan tebal dua tripleks melamin $5 \mathrm{~mm}$ Mal Frame di susun pada rangka kayu $4 \mathrm{~cm}$ x $6 \mathrm{~cm}$ (Gambar 5.b). Kontur cetakan core lambung bagian dalam dibuat dengan tripleks melamin dilengkungkan mengikuti permukaan frame multiplek dan dipaku sehingga membentuk kontur lambung perahu bagian dalam (Gambar 5.c). Cetakan core lambung dalam dimasukkan ke cetakan core lambung luar untuk pengecekan ketebalan rongga diantara cetakan dalam dan luar (Gambar 5.d). Setelah terukur ketebalan yang merata di seluruh bagian rongga cetakan maka letak cetakan dalam ditandai dengan garis sehingga cetakan dalam harus terletak di garis yang dibuat tersebut.

Kertas minyak ditempelkan pada cetakan luar core lambung (Gambar 6a) maupun ditempelkan di cetakan dalam core lambung dengan lem kertas (Gambar 6b). Penempelan kertas minyak bertujuan agar polyurethane rigid foam yang dicetak menjadi core lambung perahu tidak menempel di cetakan dan mudah diambil dari cetakan. Polyurethane rigid foam sebagai core lambung dibuat dengan mencampur, mengaduk dan menuangkan polyisocyanate dan polyol cair ke dalam cetakan. Perbandingan polyisocyanate dan polyol adalah $1: 1$. Volume rongga cetakan core lambung perahu $0,192 \mathrm{~m}^{3}$, untuk volume polyurethane rigid foam pengisi rongga tersebut diperlukan 1,92 liter polyisocyanate dan 1,92 liter polyol cair, namun perlu bahan yang lebih agar volume rongga cetakan core lambung dipastikan terisi semua oleh polyurethane foam. Kedua zat cair tersebut dituang pada wadah pengadukan yang sama (Gambar 6.c) kemudian diaduk dengan cepat agar terjadi reaksi (Gambar 6.d). Reaksi terjadi ditandai dengan keluarnya panas sampai bercampur sempurna dan mulai mengembang.

Saat campuran mengembang, campuran tersebut dituang ke dalam cetakan core lambung kapal (Gambar 7a). Core lambung kapal terbentuk sempurna setelah
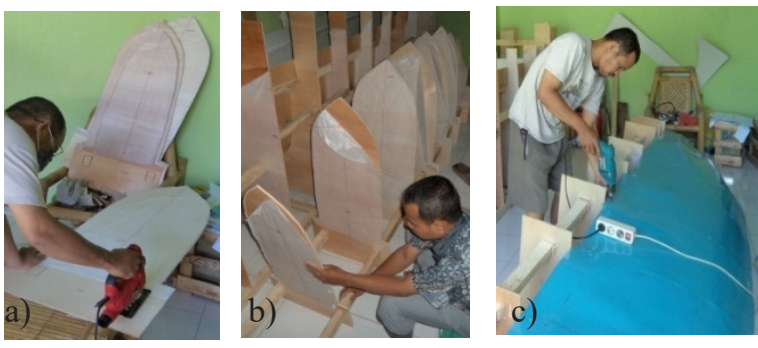

Gambar 5. Pembuatan cetakan dalam core lambung perahu .

Figure 5. Making the inside molds of the boat hull core.

Sumber: Dokumentasi pribadi

Pembuatan Perahu Nelayan Berbahan Komposit Sandwich dengan Teknik Hand lay up - Agus Dwi Catur \& Salman 

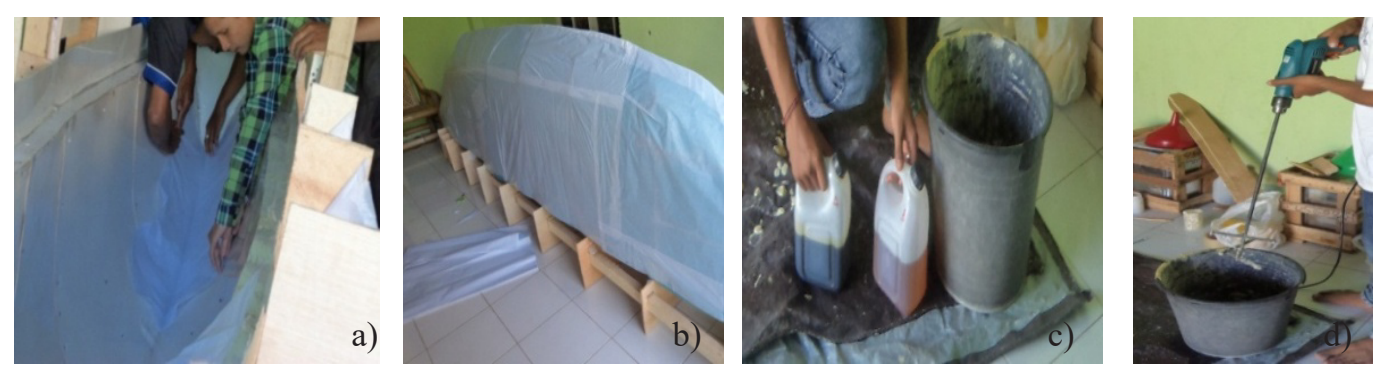

Gambar 6. a) Pelapisan kertas minyak pada cetakan luar core lambung b) Pelapisan kertas minyak pada cetakan dalam core lambung c) pencampuran polyisocyanate dan polyol d) Pengadukan campuran.

Figure 6. a) coat the paper in the outer hull core mold b) coat with a paper on the inner hull core mold c) mixing polyisocyanate and polyol d) stirring the mixture.

Sumber: Dokumentasi pribadi

polyurethane foam mengeras, kemudian dapat dilakukan pembongkaran dengan cara mencungkil cetakan dalam (Gambar 7b). Setelah cetakan dalam dilepas dengan cara mencungkilnya kemudian dilakukan pengangkatan core lambung perahu (Gambar $7 \mathrm{c}$ ). Penghalusan core dilakukan dengan mesin serut dan amplas (Gambar 7d). Kehalusan permukaan core perahu akan membuat permukaan kulit lambung perahu hasil laminasi lebih halus. Core yang halus hanya membutuhkan resin yang sedikit untuk laminasi pertama, sedangkan core yang kasar membutuhkan resin yang lebih banyak pada laminasi pertama. Penghalusan lambung pada proses berikutnya juga lebih mudah jika core lambug sudah terlebih dahulu halus.

Perlakuan alkali anyaman bambu bertujuan agar lapisan lilin pada anyaman bambu dapat larut sehingga resin dapat merekat dengan baik pada anyaman bambu. Perlakuan alkali dilakukan dengan merendam anyaman bambu pada larutan $\mathrm{NaOH}$. Anyaman bambu direndam dalam larutan $4 \% \mathrm{NaOH}$ selama 2 jam didalam wadah terbuat dari plastik untuk menghilangkan lapisan lilin serat-serat bambu. Anyaman bambu kemudian dicuci dalam air mengalir untuk menghilangkan $\mathrm{NaOH}$ yang masih membasahi serat-serat bambu. Pengeringan dilakukan dengan menjemur anyaman bambu.
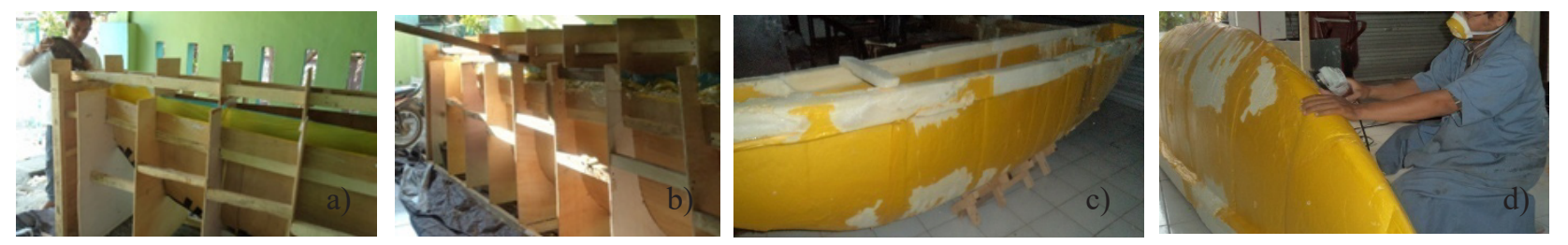

Gambar 7. a) Penuangan polyurethane foam ke dalam cetakan; b) Pengambilan core perahu dari cetakan; c) core perahu yang sudah tercetak; d) Penghalusan core perahu dengan amplas.

Figure 7. a) Casting polyurethane foam into a mold; b) retrieval boat core from the mold; c) core that has made; d) Core smoothing with sandpaper.

Sumber: Dokumentasi pribadi

JURNAL KELAUTAN NASIONAL, Vol. 15, No 2, Agustus 2020, Hal. 65-76 

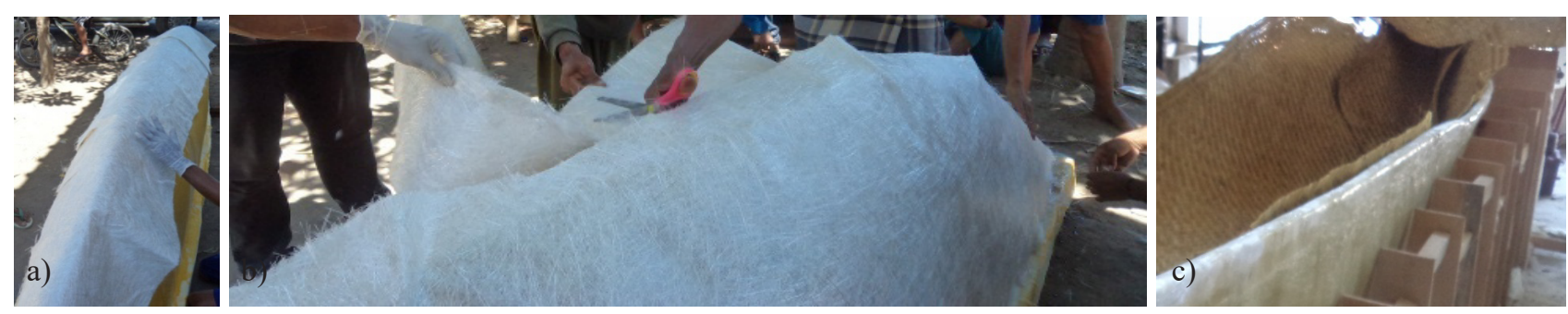

Gambar 8. Penempelan serat penguat pada lambung perahu.

Figure 8. Attaching reinforcing fibers on the hull boat.

Sumber: Dokumentasi pribadi

$200 \mathrm{gr} / \mathrm{m}^{2}$ panjang 4 meter lebar 0,4 meter (Gambar $9 b)$. Resin yang dioleskan ke fiberglass telah dicampur dengan hardener 1\% (Gambar 9a). Resin di tuang diatas permukaan fiberglass diratakan sambil ditekantekan menggunakan kuas rol maupun kapi plastik (Gambar 9c). Sebagai patokan fraksi volume fiberglass setiap pelapisan adalah $30 \%$ namun volume resin yang dioleskan perlu ditambah ketika terjadi banyak void. Void ditandai dengan warna fiberglass yang masih putih, maka resin ditambahkan pada bagian yang masih putih dan di tekan-tekan dengan capi sehingga berwarna bening (Gambar 9d). Berat resin dan berat serat penguat yang dipakai untuk laminasi pertama tertuang dalam Tabel 1 baris pertama.

Pelapisan kedua dilakukan pada seluruh permukaan core lambung bagian luar. Sama seperti pada pelapisan pertama, sebagai patokan fraksi volume fiberglass setiap pelapisan adalah $30 \%$ namun volume resin yang dioleskan perlu ditambah ketika terjadi banyak void, resin ditambahkan pada bagian yang masih putih dan di tekan-tekan dengan capi sehingga berwarna bening. Berat resin dan berat serat penguat yang dipakai untuk laminasi kedua tertuang pada Tabel 1 baris kedua. Pelapisan kulit pada lambung bagian luar dilakukan sampai 7 lapis penguat, berat resin dan berat serat penguat yang dipakai untuk masing-masing laminasi tertuang pada tabel 1 nomor 1 sampai 7. Sebelum melapis lambung bagian dalam, kulit bagian luar harus kering (curing), membutuhkan waktu 12 jam agar proses curing berjalan sempurna. Pelapisan lambung kulit dalam dengan resin yang dikuatkan dengan penguat 3 lapis, adapun susunan penguatnya seperti dalam tabel 1 nomor pelapisan 8,9 dan 10 .

Untuk membuat kontur lambung perahu yang halus maka lambung perahu harus dilapisi dengan gel coat kemudian dihaluskan dengan amplas. Gel coat dibuat dari resin dicampur dengan talk dengan perbandingan volume $1: 1$ (Gambar 10 a). Kedua bahan di aduk sampai tercampur dengan homogen sempurna. Gel coat dioleskan dengan kapi plastik dan kuas rol pada

Tabel 1. Susunan serat penguat lambung perahu dan resin yang dibutuhkan

Table 1. Composition of the hull reinforcement fibers and resin needed

\begin{tabular}{|c|c|c|c|c|c|c|}
\hline \multirow{3}{*}{$\begin{array}{l}\text { No } \\
\text { Pelapis } \\
\text { an }\end{array}$} & \multirow[t]{3}{*}{ Bahan Penguat } & \multicolumn{3}{|c|}{ Berat Serat Penguat kulit lambung luar } & \multirow{3}{*}{$\begin{array}{l}\text { Berat Penguat } \\
\text { kulit lambung } \\
\text { dalam }\end{array}$} & \multirow{3}{*}{$\begin{array}{l}\text { Berat resin } \\
\text { (gr) }\end{array}$} \\
\hline & & \multicolumn{2}{|c|}{$\begin{array}{c}\text { Penguat Lambung } \\
\text { Atas } \\
\end{array}$} & \multirow[t]{2}{*}{$\begin{array}{l}\text { Penguat Lambung } \\
\text { Bawah }\end{array}$} & & \\
\hline & & Kiri & Kanan & & & \\
\hline 1 & Fiber glass $200 \mathrm{gr} / \mathrm{m}^{2}$ & - & - & 320 & - & 382,6 \\
\hline 2 & Fiber glass $200 \mathrm{gr} / \mathrm{m}^{2}$ & 480 & 480 & 320 & - & $1.530,5$ \\
\hline 3 & Fiber glass $200 \mathrm{gr} / \mathrm{m}^{2}$ & 480 & 480 & 320 & - & $1.320,9$ \\
\hline 4 & $\begin{array}{l}\text { Anyaman bambu } \\
600 \mathrm{gr} / \mathrm{m}^{2}\end{array}$ & 1.440 & 1.440 & 960 & - & $1.6194,8$ \\
\hline 5 & Fiber glass $200 \mathrm{gr} / \mathrm{m}^{2}$ & 480 & 480 & 320 & - & $1.530,5$ \\
\hline 6 & Fiber glass $200 \mathrm{gr} / \mathrm{m}^{2}$ & 480 & 480 & 320 & - & $1.320,9$ \\
\hline 7 & Fiber glass $200 \mathrm{gr} / \mathrm{m}^{2}$ & - & - & 320 & - & 330,2 \\
\hline 8 & Fiber glass $200 \mathrm{gr} / \mathrm{m}^{2}$ & - & - & - & 640 & 660,4 \\
\hline 9 & $\begin{array}{l}\text { Anyaman bambu } \\
600 \mathrm{gr} / \mathrm{m}^{2}\end{array}$ & - & - & - & 1.920 & $8.097,4$ \\
\hline 10 & Fiber glass $200 \mathrm{gr} / \mathrm{m}^{2}$ & - & - & - & 640 & 660,4 \\
\hline
\end{tabular}

Pembuatan Perahu Nelayan Berbahan Komposit Sandwich dengan Teknik Hand lay up - Agus Dwi Catur \& Salman 

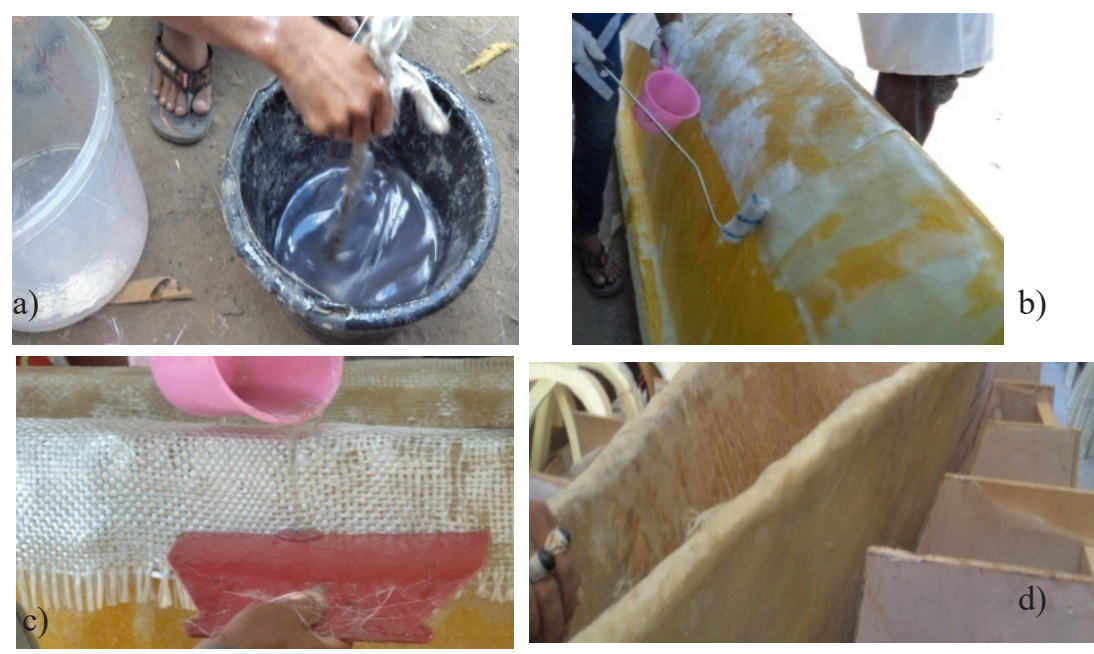

Gambar 9. Pelapisan core lambung membentuk kulit bagian luar dan dalam.

Figure 9. Core hull coating formed the outer and inner skin.

Sumber: Dokumentasi pribadi

lambung perahu (Gambar 10 b), jumlah bahan tertuang dalam Tabel 2. Setelah gel coat kering lambung perahu diamplas agar halus dengan menggunakan amplas yang digerakkan dengan mesin tangan.

Baruyungan dan katir dibuat untuk menyeimbangkan perahu. Baruyungan dibuat dari kayu ukuran $8 \mathrm{~cm} \mathrm{x}$ $12 \mathrm{~cm} \times 400 \mathrm{~cm}$ melintang di atas perahu kemudian menyudut 450 menuju bawah terhubung dengan katir. Baruyungan yang mengarah ke bawah dibuat dari kayu ukuran $6 \mathrm{~cm} \times 8 \mathrm{~cm} \times 100 \mathrm{~cm}$. Baruyungan arah horisontal dan arah menyudut kebawah dihubungkan dengan kayu $6 \mathrm{~cm} \times 8 \mathrm{~cm} \times 40 \mathrm{~cm}$ dengan lem epoxy dan tali senar warna transparan (tasik) ukuran nomor 2000. Baruyungan berfungsi untuk mengikat katir (Gambar 11a), ikatannya berupa tali tasik. Baruyungan dibuat satu pasang, satu di bagian depan perahu dan satunya lagi di bagian belakang. Baruyungan menempel di perahu bagian atas diikat dengan tali nilon $3 \mathrm{~mm}$ pada dudukannya depan (Gambar 11b) dan belakang (Gambar 11c). Katir berada di kiri dan kanan perahu memanjang sejajar dengan perahu untuk alat keseimbangan. Katir berbahan pipa pralon PVC 4" AW, di dalam pralon diisi dengan polyurethane foam, di kedua ujungnya ditutup dengan penutup pipa PVC. Selain dudukan baruyungan pada gambar $11 \mathrm{~b}$ terdapat tiang layar dan dudukan tiang layar. Pada Gambar 11d, di atas perahu dipasang dudukan mesin ketinting yang terbuat dari kayu yang diikat dengan resin dan fiberglass. Pada gambar yang sama, tiang andang-andang diletakkan menempel pada baruyungan belakang. Andang-andang ditali menghubungkan tiang andang-andang dan tiang
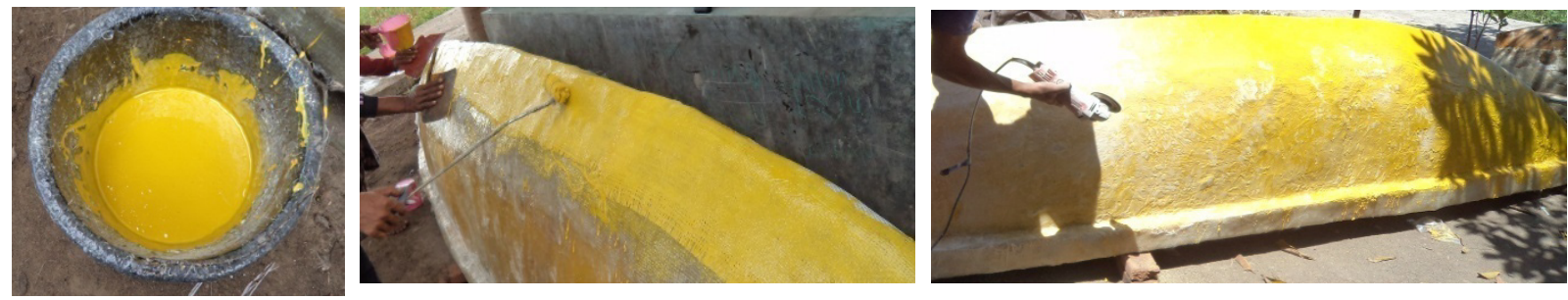

Gambar 10. a) Gelcoat; b) Pelapisan dengan gelcoat; c) Pengamplasan lambung perahu.

Figure 10. a) Gelcoat; b) Gelcoat coating with; c) Sanding the hull of the boat. Sumber: Dokumentasi pribadi

Tabel 2. bahan pendempulan lambung

Table 2. hull coating material

\begin{tabular}{lll}
\hline $\begin{array}{l}\text { volume talk } \\
\text { (fraksi volume } \\
\text { talk } \mathbf{5 0} \% \text { ) }\end{array}$ & Vol resin & $\begin{array}{l}\text { berat resin } \\
\text { (gr) }\end{array}$ \\
\hline 9600 & 9600 & 11174,4 \\
\hline
\end{tabular}

JURNAL KELAUTAN NASIONAL, Vol. 15, No 2, Agustus 2020, Hal. 65-76 

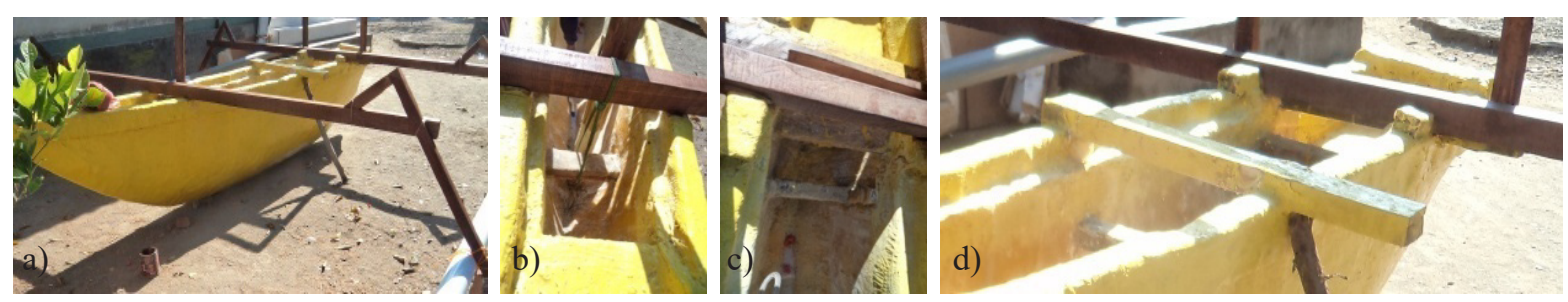

Gambar 11. Bagian perahu yang dibuat setelah pembuatan lambung selesai.

Figure 11. Parts of the boat are made after the manufacture of the hull is finished. Sumber: Dokumentasi pribadi

layar. Andang-andang berfungsi untuk mengurai jala ikan ketika akan diceburkan ke laut agar lebih mudah. Andang-andang dan tiangnya terbuat dari kayu berpenampang $4 \mathrm{~cm} \times 6 \mathrm{~cm}$.

Rekap bahan habis pakai dan kegunaannya untuk membuat perahu nelayan berbahan komposit sandwich tertera dalam Tabel 3. Bahan tersebut dipakai mulai dari membuat cetakan core, menghaluskan core, melaminasi core, melapisi lambung, menghaluskan lambung, membuat baruyungan, katir, andang-andang dan merangkainya menjadi perahu serta pengecatan. Bahan tersebut seperti polyurethane side - A B, resin polyester, hardener, pigmen, talc, tali senar dapat diperoleh dengan mudah di toko yang menjual alat-alat kebutuhan nelayan. Polyurethane side - A B juga dapat

Tabel 3. Bahan habis pakai untuk membuat perahu nelayan

Table 3. Consumable materials for making fishing boat

\begin{tabular}{|c|c|c|c|c|}
\hline No & Jenis Bahan & Kegunaan & Satuan & Jumlah \\
\hline 1 & Polyurethane side-A dan side-B & Membuat core lambung perahu & Liter & 5 \\
\hline 2 & Resin polyester Yukalac 157 & Membuat kulit lambung perahu & $\mathrm{Kg}$ & 43,2 \\
\hline 3 & Hardener & Membuat kulit lambung perahu & Ons & 4,3 \\
\hline 4 & Fiber glass $200 \mathrm{gr} / \mathrm{m} 2$ & Membuat kulit lambung perahu & $\mathrm{Kg}$ & 7,040 \\
\hline 5 & Anyaman strip bambu & Membuat kulit lambung perahu & $\mathrm{Kg}$ & 5,760 \\
\hline 6 & Pigmen kuning & Mewarnai kulit lambung perahu & Ml & 100 \\
\hline 7 & Talk & Bahan dempul lambung perahu & $\mathrm{Kg}$ & 10 \\
\hline 8 & Kuas rol & Meratakan resin & Buah & 4 \\
\hline 9 & Kuas 2,5" & Meratakan resin & Buah & 5 \\
\hline 10 & Capi plastic & Meratakan resin & Buah & 16 \\
\hline 11 & Mata gerinda & Menghaluskan kulit lambung & Buah & 5 \\
\hline 12 & Mata Amplas & Menghaluskan kulit lambung & Buah & 10 \\
\hline 13 & Cat & Mewarnai kulit lambung perahu & $\mathrm{ml}$ & 500 \\
\hline 14 & Thinner & Mewarnai kulit lambung perahu & $\mathrm{ml}$ & 500 \\
\hline 15 & Kertas minyak A0 & Melapisi cetakan core lambung & lembar & 32 \\
\hline 16 & Lem 100 gr & Melapisi cetakan core lambung & botol & 1 \\
\hline 17 & $\mathrm{NaOH}$ Kristal & perlakuan alkali anyaman bamboo & $\mathrm{Kg}$ & 2 \\
\hline 18 & Lem cyanocrylate etil (lem G) $5 \mathrm{ml}$ & Merekatkan anyaman strip bambu ke core & botol & 2 \\
\hline 19 & Multipleks $12 \mathrm{~mm}$ & Membuat cetakan core lambung perahu & lembar & 5 \\
\hline 20 & Triplek melamin & Membuat cetakan core lambung perahu & lembar & 5 \\
\hline 21 & Paku & Membuat cetakan core lambung perahu & $\mathrm{Kg}$ & 1 \\
\hline 22 & Pilles & Membuat cetakan core lambung perahu & $\mathrm{Kg}$ & 1 \\
\hline 23 & Kayu $4 \mathrm{~cm} \times 6 \mathrm{~cm} \mathrm{x} 400 \mathrm{~cm}$ & $\begin{array}{l}\text { Membuat andang-andang dan cetakan core } \\
\text { lambung perahu }\end{array}$ & lonjor & 15 \\
\hline 24 & Pipa PVC 4", 4 m & Membuat cadik & lonjor & 3 \\
\hline 25 & Lem PVC & Menyambung cadik & botol & 2 \\
\hline 26 & Kayu $8 \mathrm{~cm} \mathrm{x} 12 \mathrm{~cm}$ x $400 \mathrm{~cm}$ & Bahan baruyungan & lonjor & 2 \\
\hline 27 & Kayu $6 \mathrm{~cm} \times 8 \mathrm{~cm} \times 400 \mathrm{~cm}$ & Bahan baruyungan & lonjor & 6 \\
\hline 28 & Tali senar & Merekatkan cadik, baruyungan dan katir & ikat & 1 \\
\hline 29 & Tali nilon $6 \mathrm{~mm}$ & Merekatkan cadik, baruyungan dan katir & ikat & 1 \\
\hline 30 & Lem Epoksi & Merekatkan cadik, baruyungan dan katir & $\begin{array}{l}\text { botol } \\
250 \mathrm{gr}\end{array}$ & 1 \\
\hline
\end{tabular}

Pembuatan Perahu Nelayan Berbahan Komposit Sandwich dengan Teknik Hand lay up - Agus Dwi Catur \& Salman 
Tabel 4. Peralatan untuk membuat perahu nelayan

Table 4. Equipment for making fishing boat

\begin{tabular}{lllll}
\hline No & Nama & Kegunaan & satuan & Jumlah \\
\hline 1 & Pensil, penggaris, busur & Membuat mal cetakan dan rangkanya & Set & 1 \\
2 & Palu & Membuat cetakan core perahu & Buah & 1 \\
3 & Obeng & Membuat cetakan core perahu & Buah & 1 \\
4 & Mesin gergaji & Membuat cetakan, baruyungan, cadik. & Unit & 1 \\
5 & Mesin serut & Meratakan kontur core, meratakan kayu & Unit & 1 \\
& & baruyungan dan anjang-anjang. & & \\
6 & Mesin gerinda & Menghaluskan kontur core dan lambung & Unit & 1 \\
7 & Mesin pengaduk resin & Mencampur resin, hardener dan talk & Unit & 1 \\
8 & Ember 10 liter & Tempat mengaduk adonan & Buah & 1 \\
9 & Ember 65 liter & Perlakuan alkali anyaman bambu & Buah & 1
\end{tabular}

diperoleh di toko alat-alat mesin pendingin sebagai isolator panas. Sedangkan bahan yang lain dapat diperoleh di toko bangunan. Jumlah bahan pada Tabel 3 tersebut merupakan rata-rata dari tiga kali pembuatan perahu dengan satu cetakan core.

Kebutuhan alat tidak habis pakai untuk pembuatan perahu dengan teknik hand lay up di rekap dalam Tabel 4. Dapat dilihat pada tabel bahwa teknik hand lay up tidak memerlukan peralatan yang banyak maupun canggih sehingga mudah diterapkan bahkan oleh nelayan tradisional. Cetakan core perahu dibuat dengan peralatan yang sederhana yaitu alat tulis, palu, obeng mesin gergaji tangan. Mesin gergaji tangan berfungsi untuk memotong kayu, multipleks rangka cetak dan tripleks melamin cetakan. Palu dan obeng berfungsi untuk memukul dan mengencangkan paku maupun sekrup guna menyatukan rangka cetakan dan lembar cetakan. Pengadukan polyurethane side-A dan side-B dilakukan dengan mesin pengaduk elektrik tangan. Adonan resin dengan hardener dan talk juga dapat dilakukan dengan mesin pengaduk resin bertenaga listrik namun pekerjaan ini dapat juga dilakukan dengan pengaduk kayu yang digerakkan tangan. Pengadukan adonan resin dan hardener dilakukan dengan kayu oleh tangan. Jika pengadukan resin dengan mesin menyebabkan udara ikut masuk ke dalam adonan, agar udara terjebak berkurang maka resin ditunggu beberapa saat untuk kemudian dioleskan

Mesin serut digunakan untuk meratakan kontur core, alat ini berpenggerak listrik namun alat ini dapat digantikan dengan alat serut dorong tangan. Mesin gerinda tangan digunakan untuk meratakan kontur core maupun lambung yang telah dilaminasi dengan mata potong maupun mata amplas. Alat ini berpenggerak listrik, namun alat ini bisa digantikan dengan gergaji tangan dan amplas gosok tangan. Sedang peralatan lain adalah ember untuk mencampur adonan dan perlakuan alkali anyaman strip bambu. Peralatan yang disebutkan dalam Tabel 4 adalah peralatan pertukangan yang sering dipakai oleh tukang kayu sehingga alat ini mudah diperoleh dan mudah dioperasikan.

Dalam penelitian ini 1 orang hari artinya satu orang bekerja selama 1 hari yaitu dari jam 8.00 sampai dengan jam 16.00 dengan waktu istirahat 1 jam dari jam 11.30 sampai dengan 12.30. Pencetakan dan perataan core lambung perahu dilakukan oleh 2 orang selama setengah hari. Pekerjaan yang dilakukan adalah

Tabel 5. Jumlah Tenaga kerja untuk membuat perahu nelayan Table 5. The amount of labor to make fishing boat

\begin{tabular}{ll}
\hline Pekerjaan & Jumlah (orang hari) \\
\hline Mencetak core dan meratakan kontur core & 1 \\
Melaminasi lambung luar & 4 \\
Melaminasi lambung dalam & 3 \\
Pendempulan (gelcoat) & 2 \\
Pengamplasan dempul dan pengecatan & 2 \\
Pembuatan baruyungan, katir & 2 \\
\hline Total & 14 \\
\hline
\end{tabular}

JURNAL KELAUTAN NASIONAL, Vol. 15, No 2, Agustus 2020, Hal. 65-76 
melapisi cetakan dengan kertas minyak, mencampur dan menuang polyurethane side-A dan side-B, mengeluarkan core dari cetakan dan menghaluskan permukaan core. Melaminasi lambung luar dilakukan oleh 2 orang selama 2 hari, sedangkan melaminasi lambung dalam dilakukan oleh 2 orang selama 1,5 hari. Pendempulan dilakukan oleh 2 orang selama 1 hari, sedangkan pengamplasan dempul dan pengecatan lambung dilakukan oleh 2 orang selama 1 hari. Pekerjaan terakhir adalah pembuatan baruyungan dan katir serta dudukannya, pekerjaan ini dilakukan oleh 2 orang selama 1 hari. Pengerjaan pembuatan perahu nelayan berbahan komposit sandwich memerlukan tenaga manusia total sebanyak 14 orang hari seperti yang tercantum dalam Tabel 5.

\section{KESIMPULAN DAN SARAN}

1. Teknik hand lay up dapat diterapkan pada pembuatan perahu nelayan berbahan komposit sandwich.

2. Bahan untuk membuat perahu nelayan berbahan komposit sandwich mudah di dapat dan dalam jumlah yang terbatas.

3. Teknik hand lay up tidak memerlukan peralatan yang banyak maupun canggih sehingga mudah diterapkan.

4. Pengerjaan pembuatan perahu nelayan berbahan komposit sandwich memerlukan tenaga manusia sebanyak 14 orang hari.

\section{UCAPAN TERIMA KASIH}

Penulis ucapkan terimakasih kepada pengelola Direktorat Riset dan Pengabdian Masyarakat, Ditjen Penguatan Risbang, Kemenristek Dikti yang telah membiayai penelitian ini melalui skema penelitian dengan nomor perjanjian penugasan 030/SP2H/LT/ DRPM/II/2016. Penulis Juga ucapkan terimakasih kepada nelayan Desa Kuranji Labuapi Lombok Barat atas partisipasinya dalam penelitian ini.

\section{DAFTAR PUSTAKA}

Bansal., Arun, K. \& Zoolagud, S. S. (2002). Bamboo composites: Material of the future, Journal of Bamboo and Rattan, 9(1), 119-130.

Catur, A. D. (2009), Berat Jenis Komposit Sandwich Matrik Polyester Diperkuat Serat Nanas dan Filler Flyash dengan Honeycomb Core dari
Kertas Bekas, Seminar Nasional dan Pameran Hasil-hasil Penelitian, Lembaga Penelitian Universitas Mataram.

Catur, A. D. (2015). Load weight of boat : Experimental approach and hydrostatics calculation. Proceedings International Conference on Mathematics, Sciences and Education, University of Mataram, Lombok Island, Indonesia, November 4-5, 2015

East coast. (2013), Guide to Glass Reinforced Plastic (GRP),http://www.ecfibreglasssupplies.co.uk/tGlassReinforcedPlastics.aspx.

Greene, E. (1999). marine composites, second edition, eric greene associates incs, annapolis maryland

Jain, S., Kumar, R., \& Jindal, U. P. (1992). Mechanical behaviour of bamboo and bamboo composites, Journal of Material Science, 27(17), 4598-4604.

Jung-Seok Kim, Sang-Jin Lee, Kwang-Bok Shin, (2007). Manufacturing and structural safety evaluation of a composite train carbody, Composite Structures, 78, 468-476.

Manik, P., Chrismianto, D., \& Hadi, E. S. (2005). Kajian Teknis Penggunaan Serat Bambu Sebagai Alternatif Bahan Komposit Pembuatan Kulit Kapal, Ditinjau dari Kekuatan Bending dan Kekuatan Impact, Laporan Penelitian, Fakultas Teknik, Universitas Diponegoro.

Materials Sciences Corporation (2002), Composite Material Handbook Volume 3: Polymer Matrix Composite, material usage, design and analysis, MIL-HDBK-17 Secretariat, 500 Office Center Drive, Suite 250, Fort Washington, PA 19034.

Shukla, K. S., \& Janardhan Prasad. (1988). Reconstituted wood from bamboo for structural uses. Journal of the Indian Academy of Wood Science, 19(1), 19-27.

Shukla, N. K., Singh, R. S., \& Sanyal, S. N. (1988). Strength properties of eleven bamboo species and study of some factors affecting strength. of the Indian Academy of Wood Science, 19(2), 6380.

Thwe, (2002). Effects of environmental aging on the mechanical properties of bamboo-glass fiber 
reinforced polymer matrix hybrid composites, Composites Part A: Applied Science and Manufacturing, 33(1), 43-52.

Xiaobo Li. (2004). Physical, Chemical, and Mechanical Properties of Bamboo and Its Utilization Potential for Fiberboard Manufacturing, A Thesis, Graduate Faulty of the Louisiana State University and Agriculture and Mechanical College.

Young, G. (2013), e-frienly surfboards: the bamboo evolution. http://www.bamboosurfboardshawaii. com. 